\title{
TL estimation of ages of pottery fragments recovered from granite caves in the NW coast of Spain
}

\author{
SANJURJO-SÁNCHEZ, J. ${ }^{1}$, VIDAL ROMANÍ, J. R. ${ }^{1}$, VAQUEIRO, M. ${ }^{2}$, COSTAS \\ VÁZQUEZ, R. ${ }^{2}$ and GRANDAL D'ANGLADE, A. ${ }^{1}$ \\ (1) Instituto Universitario de Geología "Isidro Parga Pondal", Universidade da Coruña, Campus de \\ Elviña, 15071 A Coruña (Spain), jsanjurjo@udc.es, xemoncho@udc.es, xeaurora@udc.es \\ (2) Clube Espeleolóxico Trapa, c/Manuel de Castro 8-3D. 36210 Vigo (España), mvaqueiro@frioya.es
}

https://doi.org/10.17979/cadlaxe.2013.37.0.3584

\begin{abstract}
Granite caves and cavities are geomorphological environments associated with underground water flows with a strong turbulent regime linked to seasonality. Though not much studied, they have a great sedimentary and geomorphological interest but sometimes also archaeological because remains of human activity (mainly lithic industry and pottery). Pottery remains appear either exposed or buried and may be characterised mineralogically and dated by thermoluminescence (TL). Water dynamics justifies erosion and fragmentation of ceramic remains which appear broken and spread inside the cavities. This fact hinders their dating due to the small size of the fragments and the disappearance of the original sedimentary context, which does not allow the calculation of part of the received annual radiation dose. In this work, the results from the dating and the estimation of ages of different ceramic fragments of several granite caves of Galicia are presented. The obtained ages go from Medieval (1 ka BP) to Roman or pre-Roman (2 ka BP), Chalcolithic (6 ka BP) and even the beginning of the Neolithic (7 ka BP).
\end{abstract}

Key words: Thermoluminescence, pottery, pseudokarst, granite caves. 


\section{INTRODUCTION}

In the granitic massifs there are cavities similar to the ones normally found in karstic areas, though of smaller size. These caves are not very usual and of several dozens or hundreds of meters long (TWIDALE and VIDAL ROMANÍ, 2005). They are of great interest for archaeology as archaeological remains are frequently found inside them. In the western coast of Galicia and North of Portugal, there are lots of granite caves where traces of human presence have been found, theoretically from the Neolithic, Copper Age, Bronze Age to the present as the morphological typology and decoration of the pottery remains show, though absolute dating has not been performed up to now (VIDAL ROMANÍ et al., 2010). The aim of this paper is to present the first age estimations obtained by Thermoluminescence (TL) from pottery fragments found in granite caves of the western coast of Galicia, as well as to study the problems when dating in these types of sedimentary environments.

\section{STUDY AREA}

Evidences of occupation have been found in different caves of the western gra- nitic littoral of Galicia. In this work, pottery samples collected in 3 of these granite cavities (Table 1; Figure1) were selected to estimate their ages by TL: O Folón (Vigo), Trapa (Vigo), O Cebro and Peñafiel (O Pindo, A Coruña) which were provided by archaeologists due to their small size and null scientific interest, and to the absence of identifiable typological characters (GROBA and MÉNDEZ, 2008). The samples appeared on surface, on the floor of the cavities or in rock fissures, except for one which was a pottery remain found in primary position (in situ), buried in the sediments. Moreover, a sample of pottery from a limestone cave of the southwest of Galicia (Rebolal) was taken to estimate its age and to identify the problems that may exist in dating pottery in caves of different lithology. The main problems to be solved are the ones related to the calculation of annual dose, due to particular features of the granite cavities: most of the pottery could have been dragged by water fluxes. Therefore, we have performed estimations on the fragments considered as "not transported", as perhaps they underwent less or null transportation from their original location. 


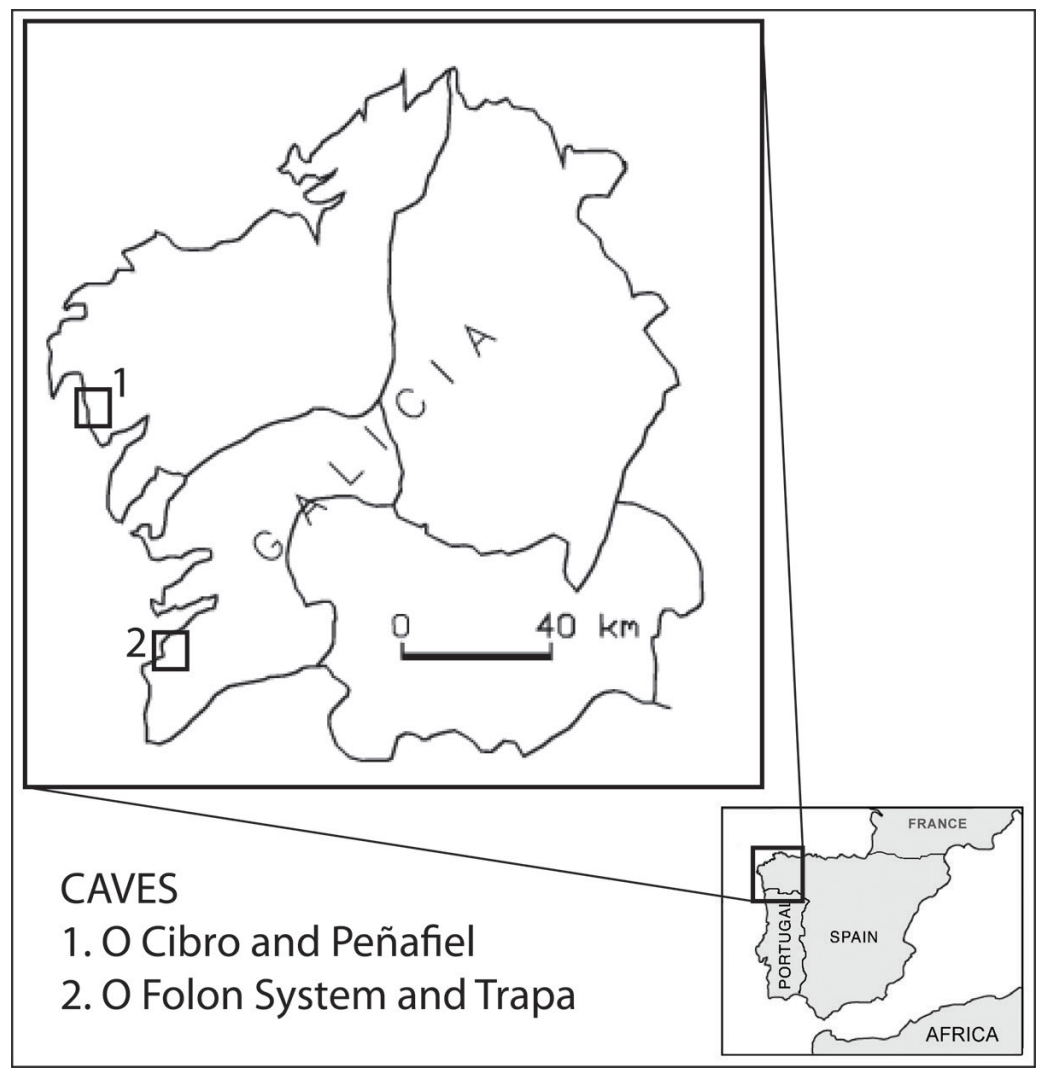

Figure 1. Map of Galicia (NW Spain) with the area of the granite cavities from which the study samples were obtained. 
2. DATING BY THERMOLUMINESCENCE IN PSEUDOKARSTIC ENVIRONMENT

Luminescence is the property of the minerals to emit light as the response to an external stimulus. In crystalline materials (minerals), the environmental ionizing radiation causes the excitation of electrons of the atoms which form part of the crystal lattice (e.g. of the quartz) so that these excited electrons are ejected from the valence band and release energy (normally as photons) to recover their initial energy state (returning to the valence band). As the crystal lattices are not perfect, mainly due to impurities in their composition (e.g. substitutions of $\mathrm{Si}$ atoms for $\mathrm{Al}$, $\mathrm{Fe}$, etc. in quartz), many of these electrons are trapped in stable potential holes called "electron traps" between the valence and the conduction bands. So, in an environment in which a mineral is exposed to constant ionizing radiation (e.g., inside a sediment), an accumulation of charge is produced, growing in a constant way with time. This charge accumulation is proportional to the energy absorbed by the mineral, and therefore, the energy dose received along the time. The stimulation of the crystal through light (optically stimulated luminescence, OSL) or heating (thermoluminescence, TL) results in the excitation of some of the trapped electrons which recombines going back to the valence band and releasing the energy excess as light. This light emission is known as luminescence. This behaviour of the electrons in crystals allows knowing the time elapsed since the moment the archaeological materials, in this case the pottery, were heated for the last time, i.e., fired during their elaboration process. Thus, after an exposure of the mineral to heat, the accumulated energy is released and the mineral is discharged, i.e., the "luminescence clock" is set to zero. After firing, the pottery starts receiving radiation. Once the pottery fragment is not used any more, it is buried in sediment or deposited in a certain place. At that moment it is exposed to a constant radiation rate giving rise to the charge accumulation, and it will thus allow the dating of the material by thermoluminescence. So, the age calculation in luminescence requires the estimation of two factors: the Equivalent Dose $\left(D_{e}\right)$, which is the absorbed dose, and the Annual Dose ( $D_{r}$ ), which is the received dose of ionizing radiation rate. The ratio between both doses provides the age $(A)$ :

$$
A=\frac{D_{e}}{D_{r}}
$$

$D_{e}$ is generally expressed in Gy $(1 \mathrm{~Gy}=1 \mathrm{~J} /$ $\mathrm{kg}$ ) while $D_{r}$ in mGy/year or Gy/ka. $D_{e}$ is measured in a Luminescence reader. There are several protocols of measurement based on TL and OSL. $D_{r}$ is calculated measuring the content in radioactive elements by geochemical methods, or the activity of radioactive isotopes in the dated material and the environment. Alternatively, it is possible to measure the gamma radiation rate in situ in the environment by means of dosimeters (TLDs) which have a high sensitivity to low radiation rates, or with a portable gamma spectrometer.

Ionizing radiations are basically of three types: alpha $(\alpha)$, beta $(\beta)$ and gamma $(\gamma)$. The radiation rate of the environment that receives the mineral to be used for luminescence has several components: two internal and two external. This is due to the fact that the alpha and beta radiations have very short range, some micrometers in the first case and few millimetres in the second. 
Both are the internal components, and are so defined because they come from the same analysed sample, and typically form around $70 \%$ of the radiation dose (AITKEN, 1985). Therefore, we could transform the age equation of the luminescence as follows: where $D_{\alpha}$ corresponds to the alpha dose, $D_{\beta}$ to the beta dose, $D_{\gamma}$ to the gamma dose and $D_{\text {c }}$ to the cosmic ray dose.

$$
A=\frac{D_{e}}{D_{\alpha}+D_{\beta}+D_{\gamma}+D_{c}}
$$

The external components of $D_{r}$ are the gamma $\left(D_{\gamma}\right)$ and the cosmic rates $\left(D_{c}\right)$. The cosmic radiation consists of a set of particles charged with high energy (atomic nuclei, electrons, poltrons and other subatomic particles) that go into the Earth's atmosphere from all directions whose origin is outside the Solar System. Their effect in all the ionizing radiation that affects a mineral on the Earth's surface is little, and it is easily calculated knowing certain parameters like latitude, altitude, density of the sediment or material which the cosmic radiation must go through before reaching the mineral of interest by means of the procedure described by Prescott and Hutton (1994).

The gamma radiation has a greater range than alpha and beta (about 25-30 cm). For pottery, this radiation may be divided into two subcomponents of the sample: internal and external. The gamma radiation of the internal component of the sample comes from the composition in radioactive elements of the material to be dated. In case of a pottery, the internal radiation comes from the radioisotopes it contains, mainly unstable isotopes of $\mathrm{U}$, Th and $\mathrm{K}$. So, analysing the content of these elements in the sample, it may be calculated relatively easily, considering the dimensions of the sample. The external gamma radiation comes from the sediment or the material in which the sample is, or located in its close surrounding. It is calculated by means of three-dimensional geometric models (infinite matrix assumption) from the radioactive concentration of the sediment that surrounds the sample and usually consists of $25-30 \%$ of the total annual dose. In the study case, the pottery found in secondary position (different from the position in which they were deposited in the ground) and the absence of sediments in most cases poses a great difficulty for the dating by luminescence. The absence of sediment implies the impossibility of measuring the radioactivity rate, and therefore the impossibility of calculating the external gamma dose rate. However, when considering fragments of pottery with absence of traces that indicate they had been transported significantly, we can assume that they were deposited into the cave or nearby the cave surroundings. This allows us to calculate about $70-80 \%$ of annual dose and thus obtain age estimations.

The most suitable mineral for dating by luminescence is quartz, given its ubiquity in sediments and archaeological materials, its strength to weathering; also the luminescence signal that exhibits is stable with time (considering a geological timescale), different from what happens with most of the minerals. Notwithstanding, most of the pottery present a low proportion of quartz; so, if this proportion is not enough, feldspars or a polymineral mixture (quartz, feldspar and clays) may be used. In both cases, the signal may be unstable with respect to time due to a phenomenon known as "anomalous fading". This loss of luminescence signal implies the underestimation of ages, and there are several types of tests called "fading tests" to correct it (AITKEN, 1985; HUNTLEY and LAMOTHE, 2001). In our case, we could isolate a grain-sized fraction of quartz for 
most of the samples, thus we could carry out the OSL measurements and the calculation of the equivalent doses in quartz for most of the samples. For some samples, due to the shortage of extracted clean quartz, the measurement in a polymineral fraction was also performed.

In all the cases, a fraction considered coarse (the size of fine sand) was used and that fraction was treated with hydrochloric acid (HF) before OSL measurement. Such chemical treatment removes the external superficial layer of the quartz and feldspar grains (a few microns). As the scope of the alpha radiation coming from the pottery matrix is a few microns, this treatment achieves the elimination of the contribution of the alpha dose to the equivalent dose we measure so that we may not consider the alpha component. However, it must be corrected the beta dose rate component that is lost when eliminating that layer, which may be about $10 \%$ of the dose when it is a mineral with HF (AITKEN, 1985). So, the equation that allows us to estimate the age in the pottery is as follows:

$$
A=\frac{D_{e}}{0.9 D_{\beta}+D_{\gamma}+D_{c}}
$$

\section{MATERIAL AND METHODS}

The age of 13 samples was estimated by TL. These samples were labelled with the name of the cave and a number, except for the ones of $\mathrm{O}$ Pindo for ones correspond to the Cibro cave and others to Peñafiel. The samples Rebolal-1 and Trapa-1 were collected in the position in which they had been deposited (primary position or in situ), while with Trapa-2 there is uncertainty though it is possible it was in primary position. The luminescence analyses were performed in the
Luminescence Laboratory of the University of A Coruña (Spain).

To estimate the equivalent dose by thermoluminescence, first a $2 \mathrm{~mm}$ surface layer were removed under red light conditions in a lab, corresponding to the external layer of each pottery fragment by sawing with a slow-motion diamond-impregnated wheel, soaking the blade in water to avoid the heating of the sample. The resulting material was carefully crushed in an agate mortar and then dried and sieved. The fraction of 90-180 $\mu \mathrm{m}$ (except for Cibro-1 for which the fraction 180-250 $\mu \mathrm{m}$ was used) was subjected to a "quartz inclusion" procedure that consists of treating the sample with a chemical treatment of $\mathrm{HCl}$ to eliminate the carbonates and a treatment of $\mathrm{H}_{2} \mathrm{O}_{2}$ to eliminate the possible presence of organic matter. After these steps, the sample was treated with HF in several steps to eliminate feldspars and leaving the quartz, eliminating the external layer of quartz. When the proportion of quartz is low and it is impossible to obtain pure quartz, an enriched-quartz polymineral fraction is obtained, which may be used for dating. Table 2 shows the sizes of grain and fractions of minerals which were used for dating.

From the minerals obtained (fractions of quartz and polymineral) TL signals were measured and equivalent doses were calculated for each sample and fraction by means of the multiple aliquot additive dose protocol (AITKEN, 1985). Before measuring the equivalent dose, it is necessary to check the stability of TL in the temperature range we will integrate. Typically, quartz shows 4 peaks, two of them are at $325^{\circ} \mathrm{C}$ and $350^{\circ} \mathrm{C}$ and time-stable at geological time scale. These peaks are the ones normally used to calculate the equivalent dose. To check their 
stability the "Plateau Test" is used (AITKEN, 1985) by means of which the natural TL signal is measured in at least one aliquot and the natural+irradiation beta TL signal in at least another one, so that a planar segment must be obtained when making the ratio between the integrals of the TL signal of both aliquots within $325^{\circ} \mathrm{C}$ and $350^{\circ} \mathrm{C}$. If the test is positive, the TL signal is considered stable and the equivalent dose may be obtained for that sample in the range of the used peaks.

The multiple aliquot additive dose protocol (AITKEN, 1985) consists of measuring the accumulated signal in the samples in several aliquots, and preparing additional aliquots that are irradiated with increasing beta doses for their TL measurement. TL signals were normalized by means of a new TL measurement after submitting the same aliquots with a new irradiation, this time with the same beta dose for all aliquots. Thus, a growth curve may be obtained indicating how the TL signal increases with the received radiation dose, and the equivalent dose may be obtained without corrections. After this process, a new irradiation is carried out so that increasing doses are applied to several sets of aliquots, thus reconstructing the growth curve of TL signal vs. given doses. This curve permits to observe the possible existence of sensitivity changes induced by the heating of the minerals during TL measurements, and to correct the supralinearity or sublinearity that is normally ob- served at the beginning of the growth curve of the luminescence, thus obtaining the final equivalent dose.

TL measurements were performed putting the minerals in stainless steel cups and heating the samples at $500^{\circ} \mathrm{C}$ at a rate of $5^{\circ} \mathrm{C}$ in nitrogen atmosphere. This was performed in an automated RISØ TL/OSL-DA-15 reader equipped with an EMI 9635 QA photomultiplier tube, and using an internal ${ }^{90} \mathrm{Sr} /{ }^{90} \mathrm{Y}$ source which provides $0.130 \pm 0.003$ Gy/s.

For the calculation of the annual dose rate, the samples were analysed by ICP-MS in order to obtain their potassium (K), uranium (U) and thorium (Th) content. With these data it is possible to calculate the beta and alpha doses in the samples and the internal gamma dose based on conversion factors (ADAMIEC and AITKEN, 1998). For the calculation of external gamma doses the concentration was measured in the same elements in rock and/or sediment samples over which the samples were found. Only in the case of the samples found in primary position, the external gamma dose was calculated from the concentration of radioactives in the sediment and rock of the environment, using a geometric model based on Guibert et al. (1998). For the rest, a similar model similar to the one of the calculation of the external gamma dose was used, but a $20 \%$ of error in the measurement of this dose was considered, considering the suggestion of Blain et al. (2010). 


\begin{tabular}{|c|c|c|c|}
\hline Sample & Cave & Environment & Position \\
\hline FOLON-1A & O Folón System & Pseudokarst & Secondary \\
\hline FOLON-1B & O Folón System & Pseudokarst & Secondary \\
\hline FOLON-5 & O Folón System & Pseudokarst & Secondary \\
\hline FOLON-6 & O Folón System & Pseudokarst & Secondary \\
\hline FOLON-7 & O Folón System & Pseudokarst & Secondary \\
\hline FOLON-8 & O Folón System & Pseudokarst & Secondary \\
\hline CIBRO-1 & Cibro, O Pindo & Pseudokarst & Secondary \\
\hline CIBRO-2 & Cibro, O Pindo & Pseudokarst & Secondary \\
\hline PEÑFIEL-1 & Peñafiel, O Pindo & Exterior & Secondary \\
\hline PENAFIEL-2 & Peñafiel, O Pindo & Exterior & Primary \\
\hline TRAPA-1 & A Trapa & Pseudokarst & Primary? \\
\hline TRAPA-2 & A Trapa & Pseudokarst & Primary \\
\hline REBOLAL-1 & Rebolal & Karst & \\
\hline
\end{tabular}

Table 1. Description of the environment and position in which the samples were found. The primary or secondary positions show if the samples were collected apparently in the place where they were deposited (primary position) or if there are traces that they underwent some transportation process (secondary).

\section{RESULTS AND DISCUSSION}

The calculated annual doses are very variable for the different pottery samples and caves (Table 2). Relative important differences are observed in the content in radioactive elements ( $\mathrm{U}$, Th and $\mathrm{K}$ ) in the different studied samples, including samples coming from the same cave. For example, it may be observed that the two samples of Trapa have totally different concentrations of the three elements. Some of these differences may be due to the fact that some elements are soluble and may be lost in the sample, as it occurs, for example, with $\mathrm{U}$, but other elements like Th are insoluble in redox conditions (as in the cave environment). This may indicate that these samples are not coetaneous or, at least, were not made using materials coming from the same place. As consequence of these differences, the calculated beta doses are also completely different. 


\begin{tabular}{|c|c|c|c|c|c|c|c|c|c|c|c|c|c|c|c|c|}
\hline 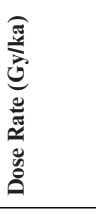 & 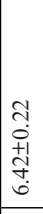 & 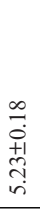 & $\begin{array}{l}m \\
\cdots \\
+1 \\
0 \\
0 \\
m \\
m\end{array}$ & $\begin{array}{l}\frac{9}{0} \\
\frac{0}{+1} \\
\infty\end{array}$ & 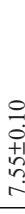 & 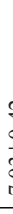 & & 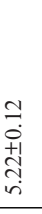 & $\begin{array}{l}\stackrel{0}{0} \\
0 \\
\text { +1 } \\
\text { +1 } \\
\stackrel{+}{+} \\
\end{array}$ & $\begin{array}{l}0 \\
0 \\
0 \\
+1 \\
+ \\
\infty \\
\infty\end{array}$ & \begin{tabular}{|l}
$\infty$ \\
0 \\
0 \\
01 \\
0 \\
in
\end{tabular} & $\begin{array}{l}\text { ले } \\
\stackrel{+}{+1} \\
+1 \\
+ \\
+\end{array}$ & & & \begin{tabular}{|l}
$\infty$ \\
0 \\
$\dot{1}$ \\
+1 \\
$\vdots$ \\
$\vdots$ \\
$i n$ \\
\end{tabular} & $\begin{array}{c}\infty \\
0 \\
+1 \\
+1 \\
\vdots \\
\vdots \\
i \\
\end{array}$ \\
\hline 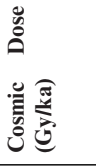 & $\begin{array}{l}\overrightarrow{0} \\
0 \\
+1 \\
0 \\
0 \\
0 \\
0\end{array}$ & $\begin{array}{l}\overline{0} \\
\text { +1 } \\
+1 \\
0 \\
0 \\
0\end{array}$ & $\begin{array}{l}\overline{0} \\
\text { +1 } \\
+1 \\
0 \\
0 \\
0\end{array}$ & $\begin{array}{l}\overline{0} \\
0 \\
+1 \\
0 \\
0 \\
0\end{array}$ & $\begin{array}{l}\overline{0} \\
\text { +1 } \\
\text { og }\end{array}$ & 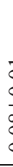 & & $\begin{array}{l}\overrightarrow{0} \\
\dot{0} \\
+1 \\
0 \\
0 \\
0 \\
0\end{array}$ & $\begin{array}{l}\overrightarrow{0} \\
0 \\
+1 \\
0 \\
0 \\
0 \\
0\end{array}$ & $\begin{array}{l}\overline{0} \\
\text { +1 } \\
+1 \\
0 \\
0 \\
0\end{array}$ & \begin{tabular}{|l}
$\overrightarrow{0}$ \\
$\dot{0}$ \\
+1 \\
0 \\
0 \\
0 \\
0
\end{tabular} & $\begin{array}{l}0 \\
0 \\
+1 \\
0 \\
0 \\
0\end{array}$ & $c$ & & 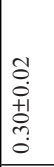 & $\begin{array}{l}\hat{D} \\
0 \\
0 \\
0 \\
0 \\
0 \\
0\end{array}$ \\
\hline 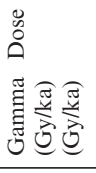 & $\begin{array}{l}a \\
0 \\
+1 \\
\infty \\
\infty \\
0 \\
0\end{array}$ & $\begin{array}{l}\bar{\sigma} \\
\text { +1 } \\
+1 \\
\infty \\
\infty \\
\infty \\
\end{array}$ & 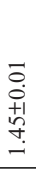 & $\begin{array}{l}\overline{0} \\
\dot{+1} \\
2 \\
\stackrel{1}{-}\end{array}$ & $\begin{array}{l}\overline{0} \\
\text { +1 } \\
\text { ? } \\
\text {. }\end{array}$ & & & 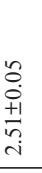 & 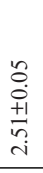 & $\begin{array}{l}\overrightarrow{0} \\
\dot{0} \\
\dot{1} \\
0 \\
\text { d. } \\
\dot{m}\end{array}$ & \begin{tabular}{|l}
$\overrightarrow{0}$ \\
$\dot{0}$ \\
11 \\
$\tilde{n}$ \\
$m$ \\
$m$
\end{tabular} & $\begin{array}{l}\stackrel{\Xi}{0} \\
\stackrel{+}{+1} \\
\stackrel{3}{i}\end{array}$ & & & 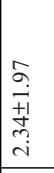 & 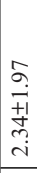 \\
\hline 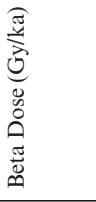 & 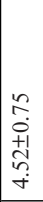 & 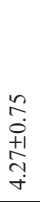 & 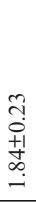 & $\begin{array}{l}\bar{n} \\
0 \\
+1 \\
0\end{array}$ & $\begin{array}{l}\bar{n} \\
+1 \\
0 \\
0\end{array}$ & 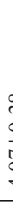 & & 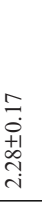 & $\begin{array}{l}= \\
0 \\
+1 \\
\text { +1 } \\
\text { in }\end{array}$ & 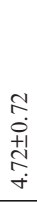 & $\mid \begin{array}{l}m \\
m \\
0 \\
+1 \\
0\end{array}$ & $\begin{array}{l}\text { I } \\
\stackrel{+}{+1} \\
\stackrel{+1}{\infty}\end{array}$ & & & 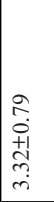 & $\begin{array}{c}2 \\
\hat{0} \\
0 \\
+1 \\
j \\
m \\
m\end{array}$ \\
\hline 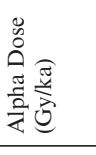 & $\begin{array}{l}\exists \\
0 \\
+1 \\
+1 \\
\infty \\
0 \\
0\end{array}$ & . & I & $\begin{array}{l}0 \\
0 \\
11\end{array}$ & ' & 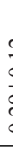 & & \begin{tabular}{l}
3 \\
0 \\
0 \\
+1 \\
1 \\
\multirow{0}{0}{} \\
0
\end{tabular} & & 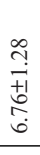 & I & \begin{tabular}{l}
0 \\
0 \\
0 \\
+1 \\
\multirow{+1}{0}{}
\end{tabular} & 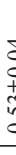 & & . & . \\
\hline$\stackrel{\widehat{d}}{\unlhd}$ & $\begin{array}{l}q \\
0 \\
+1 \\
\omega \\
c \\
i \\
i\end{array}$ & ' & 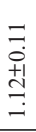 & 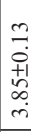 & I & 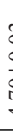 & & 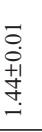 & . & 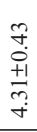 & 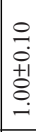 & 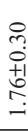 & 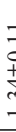 & & 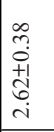 & . \\
\hline 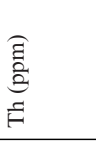 & $\begin{array}{c}\hat{a} \\
\infty \\
+1 \\
+1 \\
n \\
\infty \\
i \\
\end{array}$ & , & 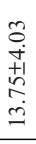 & $\underset{+}{+1}$ & ' & 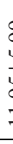 & & $\begin{array}{l}-0 \\
0 \\
0 \\
+1 \\
+ \\
0 \\
- \\
-\end{array}$ & , & $\begin{array}{l}8 \\
0 \\
0 \\
01 \\
0 \\
0 \\
m \\
m \\
\end{array}$ & 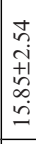 & $\begin{array}{l}\text { a } \\
\stackrel{+}{+1}\end{array}$ & $\delta$ & & 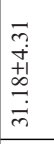 & \\
\hline 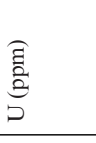 & $\begin{array}{l}\tilde{n} \\
\tilde{w} \\
+1 \\
\tilde{v} \\
\stackrel{n}{n}\end{array}$ & 1 & 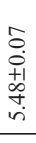 & $\begin{array}{l}5 \\
+1 \\
+1\end{array}$ & ' & 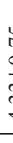 & & $\begin{array}{l}n \\
n \\
0 \\
+1 \\
n \\
n \\
n \\
n\end{array}$ & , & 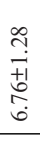 & 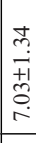 & 市 & 3 & & $\begin{array}{l}\infty \\
\infty \\
i \\
\text { in } \\
\text { a1 } \\
\alpha \\
\text { in } \\
\end{array}$ & . \\
\hline$\sum$ & $\overline{2}$ & $\stackrel{2}{2}$ & $\tilde{d}$ & $\stackrel{0}{2}$ & 0 & . & & $\stackrel{\overrightarrow{0}}{2}$ & $\approx$ & 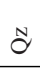 & $\approx$ & & & & $\approx$ & 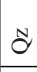 \\
\hline 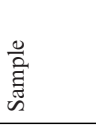 & $\begin{array}{l}\frac{7}{\frac{\pi}{\pi}} \\
0 \\
\frac{0}{2} \\
\approx\end{array}$ & & 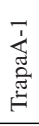 & I & & . & & 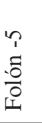 & & \begin{tabular}{|l} 
\\
: \\
.0 \\
\\
\end{tabular} & & & & & 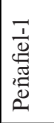 & 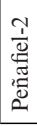 \\
\hline
\end{tabular}


Except for the two samples found in situ (Rebolal-1 and Trapa-1), all showed traces of having been moved from their original deposition/burial place. Considering the absence of significative transport, it was assumed that they had been deposited in the cave, though once there, might have been moved, which would imply variations in the gamma doses. Therefore, to obtain reliable estimations a final total deviation of at least $25 \%$ was considered for all the estimations of pottery not collected in situ, considering the suggestions of Blain et al. (2010) for the age estimation in materials that might have been exposed to several gamma doses along the time which the luminescence signal has been accumulated.

The obtained $D_{\mathrm{e}} \mathrm{s}$ were very reliable and some are very high (O Folón). For some samples, the number of measured aliquots is low (between 9 and 15 aliquots) due to the shortage of isolated quartz in the fragments of the study pottery. In these cases, the equivalent dose of the polymineral fraction of the same size was also measured, except for Peñafiel-1 and Peñafiel-2 (O Pindo). The ages obtained in these cases (quartz and polymineral) are consistent between them and with the set of dates.

The calculation of ages from the equivalent dose of the TL signals of the polymineral sub-samples allows obtaining apparent ages, because this signal is usually unstable with time due to the above-mentioned effect and known as "anomalous fading". To correct this effect and to obtain the absolute ages fading tests are carried out consisting in irradiating aliquots with beta doses and measuring them once a series of time intervals lapsed which may be of seconds, hours and some few months. Carrying out these measurements and considering different time intervals of hours, days and up to two months, different grades of fading were observed, which once corrected provide ages consistent with the ones obtained from quartz (Table 3).

The results suppose the first age estimation obtained by absolute dating methods (TL) for archaeological pottery from granite caves. As it may be observed in Table 3, some of the obtained age estimates are relatively recent (Medieval or Roman), while others give estimations of very old ages, though with a significant error.

The oldest estimations present an important error that is shown in the wide range of age they comprise. The oldest estimations are obtained in samples collected in the $\mathrm{O}$ Folón System, which is the place where a greater number of samples comes from, and that, as observed in the results (Table 3), corresponds to different prehistoric periods, which may indicate a continuous or alternate knowledge/use, but constant, of the cave. The oldest estimations correspond to Folón-5 and Folón-6 which are in a temporal interval between $11 \mathrm{ka}$ and $6.5 \mathrm{ka} \mathrm{BP}$. This interval coincides with the age of Trapa-1 (7.05 $\pm 0.86 \mathrm{ka}$ BP), a sample collected in a cavity located a few kilometres of distance. 

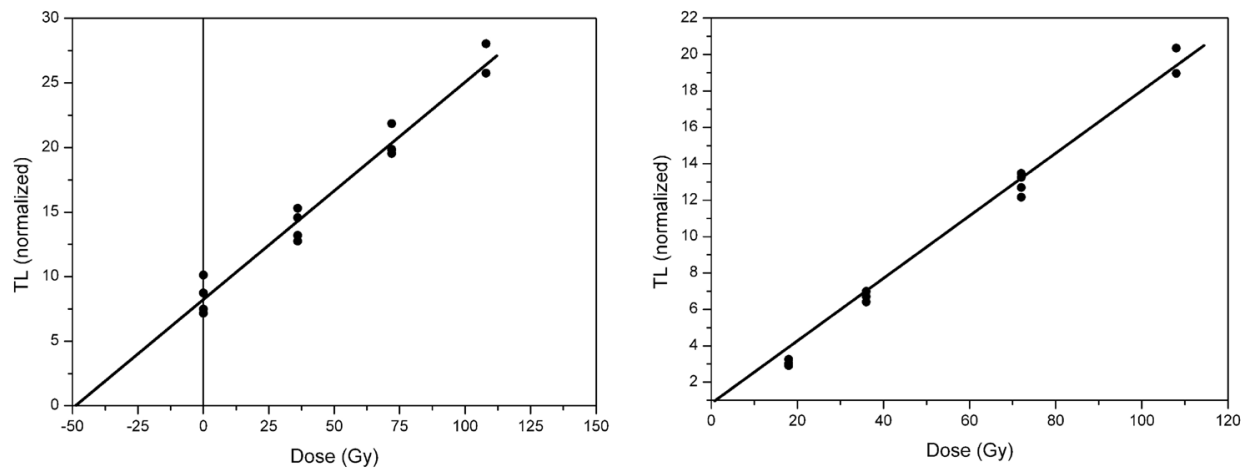

Figure 2. Example of the Folón-7 sample. Plotting of the growth curve of the TL signal with the dose added in several aliquots (a) and reconstruction of the curve after measuring the natural dose plus the added beta and addition of a second set of beta irradiations (b) following the additional dose protocol in multiple aliquot (Aitken, 1985).

Folón-1 and Folón-7 also correspond to the same period (4.5-7 ka BP) whose error overlaps with the previous one and with Trapa-1, so it may be asserted with these data that they correspond to the same period that the former samples from O Folón System. It is also probable that all of them correspond to the same period as Trapa-1. In Folón-8, a slight discrepancy is observed in the ages obtained using quartz and polymineral fractions. This discrepancy is relative, though there is an overlapping range between both ages of more than $1.5 \mathrm{ka}$, which fortuitously corresponds again to the Trapa-1 period, which seems to indicate that this sample also corresponds to this period. The relative discrepancy observed in this sample may be due to two possibilities: (a) the shortage of quartz that hinders an estimation of the more precise equivalent dose, or (b) that differences exist in the external gamma dose which affected both samples due to some change in the position impossible to be estimated. The global results of this study indicate that it is reasonable to consider this last option, which reinforces the interest that age estimation has in these environments. In spite of the uncertainty on the external gamma dose, the estimate age intervals are reliable and indicate a use of the caves of $\mathrm{O}$ Folón and Trapa in the period of $7.05 \pm 0.86 \mathrm{ka} B P$.

The rest of the samples correspond to more recent periods that go from preRoman to Medieval. The estimations do not permit to obtain more accurate data. Some of these samples correspond again to the O Folón System (Folón-6). The samples collected in O Pindo (A Coruña Province) belong to this period and to other later ones: Peñafiel-1 is pre-Roman/Roman, Cibro-2 is Roman/post-Roman, and Cibro-1 and Peñafiel-2 correspond to the Medieval Age.

As stated before, it is significant that most of the pottery samples found in $\mathrm{O}$ Folón and Trapa correspond to the same period, older than expected, and fits with the initial stages of the Neolithic in the study zone. These ages are coincident with several absolute ages obtained by ${ }^{14} \mathrm{C}$ carried out in the Iberian Peninsula (ZILHAO, 2001; ALDAY, 2009) that set the first Neolithic sites 
around $7.5 \mathrm{ka}$ BP. On the Mediterranean coast, it is more frequent to find dates of the oldest Neolithic sites between 7 and $8 \mathrm{ka} \mathrm{BP}$ (BERNABEU et al., 2011). In the southwest of Portugal, there are sites of the Mesolithic/Neolithic transition around $7.5 \mathrm{ka} \mathrm{BP}$ (DEAN et al., 2012), age that corresponds to the most likely period for this transition in Europe (ZIMMERMAN, 2012). This implies that the transition to the Neolithic in the Iberian Peninsula might be a process that affected the whole peninsula in general, though gradually, and only the absence of studies and data in the Northern-Western area may explain its exclusion from this process. The gradual expansion of the Neolithic in the Peninsula could also be quicker than it was thought some decades ago, as it is re- flected in several of the cited studies. These first age estimates in cavities of the NW peninsular coast do confirm such previous observations.

In spite of the circumstances that the pottery fragments coming from granite cavities were generally transported by water fluxes and are not found in their original sedimentary environment, thermoluminescence supposes a fundamental device to estimate ages, though it is necessary to keep progressing in this research line, especially if it is taken into account that in granite caves the strongly acid $\mathrm{pH}$ of the environment and the energy of the erosive processes contribute to a quick destruction of the bone or organic remains, susceptible of being dated by ${ }^{14} \mathrm{C}$. 


\begin{tabular}{|c|c|c|c|c|c|c|c|c|c|c|c|c|c|c|c|c|c|c|}
\hline 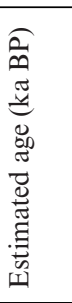 & & & & 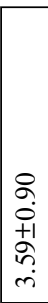 & & 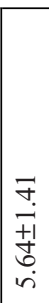 & $\begin{array}{l}\stackrel{\circ}{n} \\
\frac{+1}{\sigma} \\
\stackrel{0}{0}\end{array}$ & \begin{tabular}{l}
$\hat{m}$ \\
it \\
+1 \\
0 \\
\multirow{a}{*}{}
\end{tabular} & $\begin{array}{l}0 \\
+ \\
i \\
+1 \\
\sim \\
\infty \\
\infty \\
a\end{array}$ & $\begin{array}{l}n \\
n \\
o \\
+1 \\
\infty \\
\stackrel{1}{c}\end{array}$ & 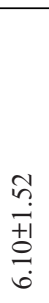 & $\begin{array}{l}\text { I } \\
\text { it } \\
+1 \\
\text { a } \\
\infty \\
\infty\end{array}$ & $\begin{array}{l}\frac{n}{+1} \\
\text { ते } \\
\text { तु }\end{array}$ & $\begin{array}{l}0 \\
+ \\
0 \\
+1 \\
\text { d. } \\
0 \\
-\end{array}$ & $\begin{array}{l}\stackrel{0}{0} \\
o \\
+1 \\
\stackrel{1}{\alpha} \\
\vdots \\
0\end{array}$ & 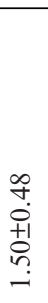 & $\begin{array}{l}\mathbb{N} \\
\stackrel{0}{0} \\
+1 \\
\stackrel{1}{0} \\
\stackrel{-}{-}\end{array}$ & 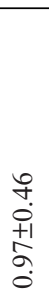 \\
\hline 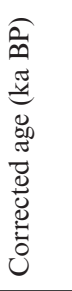 & $\begin{array}{c}0 \\
+ \\
\dot{0} \\
+1 \\
\dot{+1} \\
\dot{r}\end{array}$ & & & $\begin{array}{l}\hat{n} \\
0 \\
+1 \\
0 \\
\hat{n} \\
n\end{array}$ & & & & 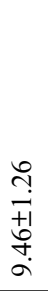 & & & & $\begin{array}{l}\text { I } \\
\text { it } \\
+1 \\
\text { aे } \\
\infty \\
\infty\end{array}$ & & & & & & \\
\hline 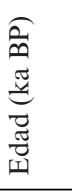 & $\begin{array}{c}n \\
n \\
0 \\
+1 \\
0 \\
\\
\text { i }\end{array}$ & 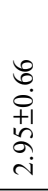 & $\begin{array}{l}0 \\
\infty \\
0 \\
+1 \\
0 \\
0 \\
i \\
r\end{array}$ & $\begin{array}{c}0 \\
n \\
0 \\
+1 \\
+1 \\
\dot{n} \\
i \\
\text { in }\end{array}$ & $\begin{array}{l}8 \\
\stackrel{0}{0} \\
0 \\
+1 \\
\stackrel{1}{\circ} \\
i\end{array}$ & $\begin{array}{l}0 \\
0 \\
0 \\
+1 \\
+1 \\
\dot{1} \\
\dot{n}\end{array}$ & $\begin{array}{l}8 \\
0 \\
0 \\
+1 \\
0 \\
0 \\
0\end{array}$ & $\begin{array}{l}8 \\
\frac{8}{+1} \\
+1 \\
\text { ñ } \\
r\end{array}$ & $\begin{array}{l}0 \\
\cdots \\
i \\
+1 \\
\omega \\
\infty \\
a\end{array}$ & 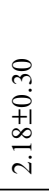 & $\begin{array}{l}0 \\
\infty \\
0 \\
+1 \\
0 \\
0 \\
0\end{array}$ & 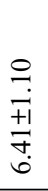 & 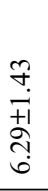 & $\begin{array}{l}\text { o } \\
+ \\
0 \\
+1 \\
\text { d. } \\
-\end{array}$ & 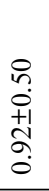 & 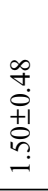 & $\begin{array}{l}\stackrel{1}{1} \\
\dot{0} \\
+1 \\
0 \\
\infty \\
-1\end{array}$ & \begin{tabular}{l}
0 \\
\multirow{0}{0}{} \\
+ \\
+1 \\
$\hat{0}$ \\
0 \\
0
\end{tabular} \\
\hline 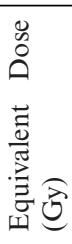 & $\begin{array}{l}+\vec{n} \\
\tilde{+} \\
+1 \\
\infty \\
\infty \\
\ddot{n}\end{array}$ & 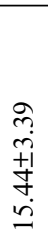 & 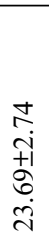 & 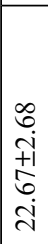 & 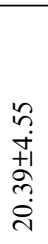 & $\begin{array}{l}n \\
6 \\
10 \\
+1 \\
6 \\
\dot{0} \\
\dot{m}\end{array}$ & 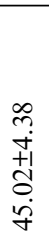 & 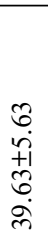 & $\begin{array}{l}\stackrel{1}{1} \\
\stackrel{0}{0} \\
+1 \\
\infty \\
0 \\
\dot{b} \\
+\end{array}$ & $\begin{array}{l}\infty \\
+ \\
\text { i } \\
\text { t1 } \\
\text { లn } \\
\infty \\
\infty\end{array}$ & $\begin{array}{l}\vec{n} \\
\stackrel{+}{+} \\
+1 \\
\stackrel{2}{a} \\
\dot{m}\end{array}$ & $\begin{array}{l}\stackrel{+}{\sim} \\
\stackrel{+}{+} \\
+1 \\
\stackrel{n}{n} \\
\stackrel{\sim}{\sim}\end{array}$ & 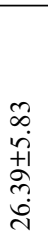 & $\begin{array}{l}\stackrel{+}{n} \\
+\underset{+1}{+1} \\
\hat{b} \\
\dot{+}\end{array}$ & 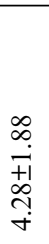 & $\begin{array}{l}\vec{m} \\
\underset{+1}{+1} \\
\stackrel{\infty}{\infty} \\
\stackrel{a}{ }\end{array}$ & $\begin{array}{l}\tilde{o} \\
\dot{d} \\
+1 \\
\text { ti } \\
\stackrel{0}{0}\end{array}$ & $\begin{array}{l}\text { ㄱ } \\
\text { it } \\
+1 \\
\infty \\
i \\
\text { in }\end{array}$ \\
\hline$\stackrel{\square}{\bar{z}}$ & $\ddot{\imath}$ & $\cong$ & $m$ & $\ddot{\sim}$ & $\stackrel{m}{2}$ & $\stackrel{\sim}{\sim}$ & $\stackrel{0}{ }$ & $\stackrel{\sim}{\sim}$ & $\cong$ & $\tilde{\lambda}$ & \pm & $\tilde{\sim}$ & $=$ & $\vec{\sim}$ & \pm & $\stackrel{\sim}{*}$ & $a$ & 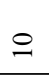 \\
\hline 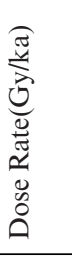 & $\begin{array}{l}\tilde{I} \\
\tilde{0} \\
+1 \\
\tilde{y} \\
\tilde{\sigma} \\
0\end{array}$ & 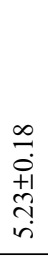 & $\begin{array}{l}m \\
\overrightarrow{0} \\
+1 \\
0 \\
m \\
m\end{array}$ & 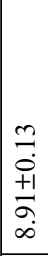 & 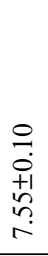 & 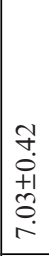 & $\begin{array}{l}\text { I } \\
\overrightarrow{0} \\
+1 \\
\text { à } \\
\stackrel{+}{r}\end{array}$ & $\begin{array}{l}\text { I } \\
\text { i } \\
+1 \\
\text { i } \\
\text { in }\end{array}$ & 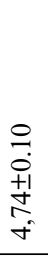 & $\begin{array}{l}0 \\
\ddot{0} \\
+1 \\
\overrightarrow{+} \\
\infty \\
\infty\end{array}$ & $\begin{array}{l}\infty \\
\dddot{0} \\
+1 \\
+1 \\
0 \\
i\end{array}$ & $\begin{array}{l}\stackrel{9}{0} \\
0 \\
+1 \\
+1 \\
\stackrel{+}{+} \\
\dot{+}\end{array}$ & & 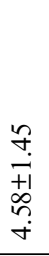 & 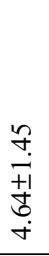 & 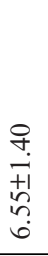 & $\begin{array}{l}\infty \\
\stackrel{\infty}{+} \\
\frac{+1}{\Delta} \\
\hat{\sigma} \\
\dot{n}\end{array}$ & $\begin{array}{l}\infty \\
0 \\
\frac{+1}{+1} \\
\hat{\alpha} \\
\hat{n}\end{array}$ \\
\hline$\Xi$ & $\overline{0}$ & $\stackrel{N}{\sigma}$ & $\stackrel{N}{\sigma}$ & $\overline{0}$ & $\stackrel{N}{\sigma}$ & $\overrightarrow{0}$ & $\stackrel{N}{O}$ & $\overline{0}$ & $\mathscr{O}$ & $\mathscr{N}$ & $\mathscr{N}$ & $\overrightarrow{0}$ & $\mathscr{d}$ & $\tilde{d}$ & $\mathscr{d}$ & $\tilde{d}$ & $\tilde{d}$ & $\stackrel{N}{\sigma}$ \\
\hline 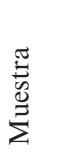 & $\begin{array}{l}7 \\
\frac{1}{\pi} \\
0 \\
0 \\
\mathscr{D} \\
\simeq\end{array}$ & & 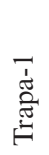 & 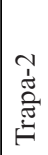 & & $\begin{array}{l}\longleftarrow \\
\vdots \\
\vdots 0 \\
0 \\
0 \\
0\end{array}$ & 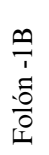 & 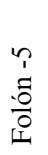 & & $\begin{array}{l}\text { 0. } \\
1 \\
\stackrel{0}{0} \\
0 \\
0\end{array}$ & 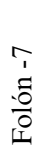 & $\begin{array}{l}\infty \\
1 \\
0 \\
0 \\
0 \\
0 \\
0\end{array}$ & & $\begin{array}{l}\overrightarrow{0} \\
\stackrel{0}{0} \\
0\end{array}$ & & $\begin{array}{l}\tilde{o} \\
\stackrel{0}{0} \\
0\end{array}$ & 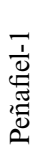 & 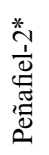 \\
\hline
\end{tabular}




\section{CONCLUSIONS}

Granite caves and cavities are environments in which archaeological remains frequently appear. The shortage or absence of sediments and the high acidity of the terrain hinder the preservation of organic remains available for dating by radiocarbon. Therefore, the only applicable method is the dating by luminescence of materials like pottery. In granite caves and cavities of the NW coast of the Iberian Peninsula, pottery fragments are frequently found. This work constitutes the first approach of estimating the age of such fragments by luminescence.

Three are the main difficulties for the dating by luminescence of archaeological pottery in these environments: the shortage of sample (dating must be performed on small-sized fragments, with very low content in quartz or minerals capable of being used for the analysis by thermoluminescence), the position of such fragments in secondary positions (not in situ), and the absence of sediments in most cases, which hinders the calculation of the complete gamma dose and gives age estimations with a high error. In spite of these difficulties, this work showed that it is possible to obtain reliable age intervals for these samples as age estimates. The estimations indicate that the caves were occupied or used by the man from the beginning of the Neolithic to the Medieval. The samples corresponding to the beginning of the Neolithic correspond to a probable period placed in $7.05 \pm 0.86 \mathrm{ka}$ BP. They are in the O Folón System and Trapa, two cavities located on the coast of the Pontevedra Province, some few kilometres between them.

\section{ACKNOWLEDGEMENTS}

The authors want to thank for the English translation to Ana Martelli Emancipato.

\section{REFERENCES}

ADAMIEC, G., AITKEN, M. (1998). Dose-rate conversion factors: Update. Ancient TL. 16:37-50.

AITKEN, M. J. (1985). Thermoluminescence Dating; Academic Press: London.

ALDAY RUÍZ, A. (2009). Late Mesolithic and Early Neolithic in the Iberian Peninsula: chronology and phases. MUNIBE, 60, 157-173.

BERNABEU AUBÁN, J., GÓMEZ PÉREZ, O., MOLÍNA BALAGUER, LL., GARCÍA BORJA, P. (2011). La cerámica Neolítica durante el VI Milenio Cal AC en el Mediterráneo central peninsular. SAGVNTVM, Papeles del Laboratorio de Arqueología de Valencia, Extra-12, 153-179.

BLAIN, S., BAILIFF, I. K., GUIBERT, P.; BOUVIER, A. and BAYLÉ, M. (2010). An intercomparison study of luminescence dating protocols and techniques applied to medieval brick samples from Normandy (France). Quaternary Geochronology. 5:311-316.

DEAN, R. M, VALENTE, M. J. and CARVALHO, A. F. (2012). The Mesolithic/ Neolithic transition on the Costa Vicentina, Portugal. Quaternary International 264, 100-108.

GROBA GONZÁLEZ, $X$ and MÉNDEZ QUINTAS, E. (2008). Human occupations during recent prehistory in the granite caves of the western coast of Galicia. Cadernos Lab. Xeolóxico de Laxe. 33:115 - 126

GUIBERT, P., BECHTEL, F., SHVOERER, M., MÜLLER, P. and BALESCU, S. A. (1998). A new method for gamma dose-rate estimation of heterogeneous 
media in TL dating. Radiation Measurements. 29:561-572.

HUNTLEY, D. J. and LAMOTHE, M. (2001). Ubiquity of anomalous fading in K-feldspars and the measurement and correction for it in optical dating. Canadian Journal of Earth Sciences. 38:10931106.

PRESCOTT, J. R. and HUTTON, J. T. (1994). Cosmic ray contributions to dose rates for luminescence and ESR dating: large depths and long-term time variations. Radiation Measurements, vol. 23, No 2-3, 497-500.

TWIDALE, C. R. and VIDAL ROMANÍ, J. R. (2005). Landforms and Geology of Granite Terrains; Balkema: London, 2005.
VIDAL ROMANÍ, J. R., SANJURJO, SÁNCHEZ, J., GRANDAL D'ANGLADE, A., VAQUEIRO RODRÍGUEZ, $M$. and FERNÁNDEZ MOSQUERA, D. (2010). Geocaracterización de yacimientos arqueológicos en medio sedimentario: cronología absoluta y relativa. Monografías, 4. Museo de Prehistoria e Arqueoloxía de Vilalba. pp.7-19.

ZILHAO, J. (2001). Radiocarbon evidence for maritime Pioneer colonization at the origins of farming in west Mediterranean Europe. PNAS, 98 (24) 14180-14185.

ZIMMERMAN, A. (2012). Cultural cycles in Central Europe during the Holocene. Quaternary International 274, 251-258. 